\title{
Role of Immunoglobulin Light Chains in AL Amyloidosis
}

\begin{abstract}
Key words: AL amyloidosis, immunoglobulin, free light chain, Bence Jones protein, stem-cell transplantation
\end{abstract}

Primary or light chain-associated (AL) amyloidosis is one of the plasma cell dyscrasias that is characterized by the deposition of amyloid fibrils in the systemic organs such as heart, liver, kidney, tongue, gastrointestinal tract, skin, and peripheral nerves. These Congophilic fibrils mostly consist of either the variable domain $\left(\mathrm{V}_{\mathrm{L}}\right)$ fragment of the monoclonal immunoglobulin ( $\mathrm{Ig}$ ) light chains or the $\mathrm{V}_{\mathrm{L}}$ plus adjacent portion of the constant domain $\left(\mathrm{C}_{\mathrm{L}}\right)$, or less commonly, the intact light chain (Bence Jones protein, BJP). In the 1960s, Osserman et al first recognized that BJPs play a direct role in the pathogenesis of primary amyloidosis (1). Subsequent studies have aimed at elucidating the relationship between the structure and property of amyloidgenic BJPs. Solomon et al demonstrated the development of amyloid deposits in mice by injection with BJPs obtained from patients with AL amyloidosis, and described the importance of certain amino acid sequences of BJPs for amyloidogenicity (2). The immunochemical and molecular analysis of Ig light chains revealed that amyloid property and organ specificity are associated with particular types of $\mathrm{V}_{\mathrm{L}}$ subgroups $(3,4)$.

Monoclonal Igs serve as important clinical markers for monitoring plasma cell dyscrasias. Unfortunately, these products are generally undetectable in serum or urine of $\mathrm{AL}$ amyloidosis patients by conventional electrophoresis techniques. Several attempts were made to establish an assay system for intact light chains, but none of these assays were used for laboratory examinations in the clinical setting because of a lack of specificity and complexity of the methods. Recently, a high-sensitive nephelometric assay for Ig light chains has been developed using latex-conjugated antibodies specific for the epitopes of free light chains but not heavy chains (5). This assay system is now available as a diagnostic kit (Freelite ${ }^{\mathrm{TM}}$, The Binding Site Ltd, Birmingham, UK).

In this issue of Internal Medicine, Matsuda and colleagues report the usefulness of this serum free light-chain assay before and after treatment in 25 Japanese patients with $\mathrm{AL}$ amyloidosis (6).

See also p 428.
They have confirmed and extended previous results indicating that this assay contributes to the diagnosis and monitoring of patients with AL amyloidosis (7-9). In fact, serum free light chains have a favorable characteristic of a short half-life for rapid assessment, but these levels are significantly affected by the glomerular filtration rate especially in patients with renal failure. Alternatively, they employed a kappa/lambda ratio of the free light chains, and revealed a potential benefit of the ratio for evaluating the response, monitoring the disease, or ultimately, for predicting the prognosis after therapy.

Treatment of AL amyloidosis has been directed toward reducing the synthesis of the amyloid precursors from plasma cells through conventional or high-dose chemotherapy. High-dose melphalan with autologous stem-cell transplantation has extended the overall survival in selected patients; however, the prognosis remains extremely poor due to the persistence of the amyloid deposits and/or organ dysfunction in most patients (10). Current studies focus on further understanding the molecular mechanism of amyloid formation and resorption, and providing new insight into the development of novel molecular-targeted therapies (11). For example, administration of monoclonal antibodies that recognize an epitope common to the beta-pleated structure of amyloid has been shown to induce marked reduction of amyloid burden in vivo model (12). In future clinical studies, this free lightchain assay will be extensively applied to the patients with plasma cell dyscrasias including multiple myeloma and AL amyloidosis.

\section{Shuji OzAKI, MD \\ Division of Transfusion Medicine, Tokushima University Hospital,} 2-50 Kuramoto-cho, Tokushima 770-8503

\section{References}

1) Osserman EF, Takatsuki K, Talal N. Multiple myeloma I. The pathogenesis of amyloidosis. Semin Hematol 1: 3-85, 1964.

2) Solomon A, Weiss DT, Pepys MB. Induction in mice of human lightchain-associated amyloidosis. Am J Pathol 140: 629-637, 1992.

3) Ozaki S, Abe M, Wolfenbarger D, Weiss DT, Solomon A. Preferential expression of human lambda-light-chain variable-region subgroups in multiple myeloma, AL amyloidosis, and Waldenstrom's macroglobulinemia. Clin Immunol Immunopathol 71: 183-189, 1994.

4) Abraham RS, Geyer SM, Price-Troska TL, et al. Immunoglobulin light chain variable $(V)$ region genes influence clinical presentation and outcome in light chain-associated amyloidosis (AL). Blood 101: 3801$3808,2003$.

5) Bradwell AR, Carr-Smith HD, Mead GP, et al. Highly sensitive, 
automated immunoassay for immunoglobulin free light chains in serum and urine. Clin Chem 47: 673-680, 2001.

6) Matsuda M, Yamada T, Gono T, et al. Serum levels of free light chain before and after chemotherapy in primary systemic AL amyloidosis. Intern Med 44: 428-433, 2005.

7) Lachmann HJ, Gallimore R, Gillmore JD, et al. Outcome in systemic AL amyloidosis in relation to changes in concentration of circulating free immunoglobulin light chains following chemotherapy. $\mathrm{Br} \mathrm{J}$ Haematol 122: 78-84, 2003.

8) Abraham RS, Katzmann JA, Clark RJ, Bradwell AR, Kyle RA, Gertz MA. Quantitative analysis of serum free light chains. A new marker for the diagnostic evaluation of primary systemic amyloidosis. Am J Clin
Pathol 119: 274-278, 2003.

9) Mead GP, Carr-Smith HD, Drayson MT, Morgan GJ, Child JA, Bradwell AR. Serum free light chains for monitoring multiple myeloma. Br J Haematol 126: 348-354, 2004.

10) Dispenzieri A, Kyle RA, Lacy MQ, et al. Superior survival in primary systemic amyloidosis patients undergoing peripheral blood stem cell transplantation: a case-control study. Blood 103: 3960-3963, 2004.

11) Merlini G, Bellotti V. Molecular mechanisms of amyloidosis. N Engl J Med 349: 583-596, 2003.

12) Solomon A, Weiss DT, Wall JS. Therapeutic potential of chimeric amyloid-reactive monoclonal antibody 11-1F4. Clin Cancer Res 9: 3831s-3838s, 2003. 